

\title{
Interactive Kinetic Architecture: Progressive Design Principles
}

\author{
Bujar Bajçinovci $^{1 *}$,Vlora Aliu', Bard Bajçinovci², Uliks Bajçinovci² \\ ${ }^{1}$ University of Prishtina, Faculty of Civil Engineering and Architecture, Kosovo. \\ ${ }^{2}$ UBT - Higher Education Institution, Department of the Architecture. Prishtina, Kosovo. \\ Email:bujar.bajcinovci@uni-pr.edu,vlora.aliu@uni-pr.edu.bb34218@ubt-uni.net,ub35398@ubt-uni.net
}

\begin{abstract}
:
Interactive architecture encompasses building automation but goes beyond it by including forms of interaction engagements and responses that may lay in pure communication purposes as well as in the emotive and artistic realm, thus entering the field of interactive art. In the coming decades, new interactive architecture process will continue to be largely implemented in to the urbanarchitectural environment. Various performative art media also embark on interactive architectural design strategies. Therefore, the combination of sensors, processors and effectors of the variable elements in the architectural structure transforms the perception and understanding of the architectural buildings from passive one into an active evolutive compositions.
\end{abstract}

Key words: Interactive, Kinetic, Architecture, Progressive, Design Principles.

\section{INTRODUCTION}

"Interactive architecture refers to the branch of architecture which deals with buildings featuring the trio of sensors, processors and effectors, embedded as a core part of its nature and functioning. Interactive architecture encompasses building automation but goes beyond it by including forms of interaction engagements and responses that may lay in pure communication purposes as well as in the emotive and artistic realm, thus entering the field of interactive art" [1]. Nowadays, and in the coming decades new interactive architecture practices will continue to be largely implemented in to the urban-architectural environment. Various performative art media also embark on interactive architectural design strategies. In addition, day-to-day life and new lifestyles will implement new virtual networks, thus, interacting with massive data exchange of automated software directed tasks. Some performative art branches like digital movie industry have accelerated so much needed contemporary vision of architects, and designers for progressive Attribution License http://creativecommons.org/licenses/by/4.0/, which permits unrestricted use, provided the original author and source are credited. 
design principles. Furthermore, movie industry has adopted very quickly new digital technologies with futuristic prediction frameworks, like the movie The Matrix, which offers a scenario that treats the reality as done in a simulation, its interactive virtual-real program allows people to access new technology devices experiencing what they think it's a reality, when in fact, only their brain impulses interreact with the loaded matrix programs [2]. However, interactive architecture brings the potential to human personalization into a context that makes people's desires, and needs constantly more active and evolving. This conceptual perception in architectural development with system of framework interactivity create not only human personal engagement with surrounding, but also create the different reference for architectural space. At the core of the contemporary architecture level, architects and digital designers are actually acknowledging the new reality and arguing to the question posed by the "Cedric Price - in the 1960": "What happens if a building or space can be continuously generated and regenerated?" [2].

\section{MATERIALS and METHODS}

The study in this paper, present the overview of progressive design principles, focusing on the framework of the Interactive Kinetic Architecture. The research method consists of empirical observation, and literature review. Study were investigated through literature review, technology advancements, documentations and conceptual drawings. The collected data also include implementing the kinetic design principles in the art media, movie industry, composition of urban structure, mobility, and in art movement.

Hence, a contemporary architect needs to be specialized in progressive design principles by applying new digital conceptual design concepts, thus, using conventional technology unconventionally, to explore the manners in which people socialize with each other and with the surrounded space. Nowadays, a contemporary architect should understand the sustainability, environment, and space in relation to the interactivity with software design framework that enables the evolutive structural transformations of a buildings, or targeted features of the buildings. The concept of interactive architecture is based largely on the demands of urbanites, architects, artists and designers of the visual art media, and surely this process of perception transformations will continue.

(C)2015 The Authors. Published by the International Academy of Sciences, Humanities, and Arts under the terms of the Creative Commons Attribution License http://creativecommons.org/licenses/by/4.0/, which permits unrestricted use, provided the original author and source are credited. 
Moreover, this unlimited area of possibilities continues to develop its multi-dimensional identity, presenting more innovative solutions in the visual architectural perception, strengthened with continuously advanced technology, firstly aimed to the increase of the quality of life and various new life style requirements [3].

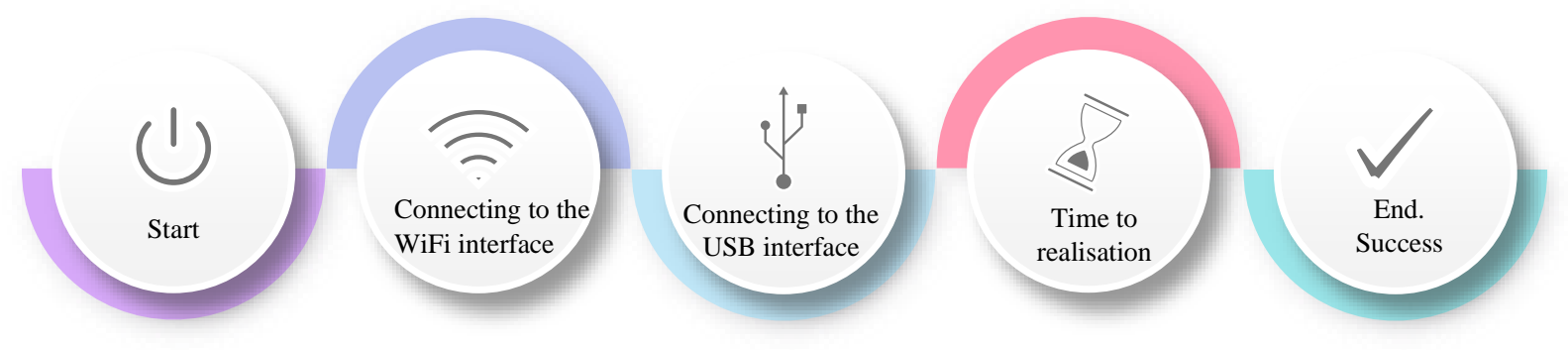

Figure 1. The software implementation process in the interactive structural architecture.

In an era of Information Technology development, architecture professionals have to think beyond the current urban demands, habitat, equipment and technology, so that the space treated by the architectural processes can coexist in a mutual environment between technology and architecture. The actual buildings are generated with the relevant technology of the present requirements, however, the conceptual architectural tendencies for the future will be empowered with invisible networks of the electronic activities in the shape of the surveillance systems, transforming the structural parts of the buildings, hence, also this technology of the future will enable a wide range of the electromagnetic systems, which can be used to change the interactivity of urbanites with urban ambience [3]. Contemporary urban and architectural concepts with interactive methods and systems distribute the need to explore beyond the present demands of urbanists and architects to analyze, examine and describe the opportunities to the unknown future for the communities to use interconnection with the technology. Therefore, the parameters of interactive architecture should be highlighted as an architecture of evolutionary relations between technology and society. It is essential to distinguish between interactive architecture, and interaction with the architecture. In this context, it is necessary to understand the urban development and the transdisciplinary interaction accomplished between cybernetics, architecture, e-control, and communication with the automated systems. This is particularly important in a new digital era where the use of technology is so easily confused with the implemented tradition so far. Nowadays, architectural 
design research and creative art processes are increasingly intertwined with interactive architecture methodologies [3]. Designing an interactive structure, is a complex notion, originally arose in the field of architecture more than two decades ago. This design process demonstrates how a whole structural system, controlled by different sensors, processors, effectors and a software interface, can respond to the needs and requirements of the individual and community. Moreover, the nature of such interaction is not linear and in one-way direction, but far more, a multi directional relation between environment, requirements, and users involved in the targeted process. Hence, in regard to the design, inter relationship of the interactive architecture, present a complex technological, conceptual and functional dilemma! In the terms of the perception, this creative realization of the architectural concepts enables users to experience architectural space in a more vibrant and more participatory fashion, transforming the classical and traditional perception of urban and architectural spaces [4].

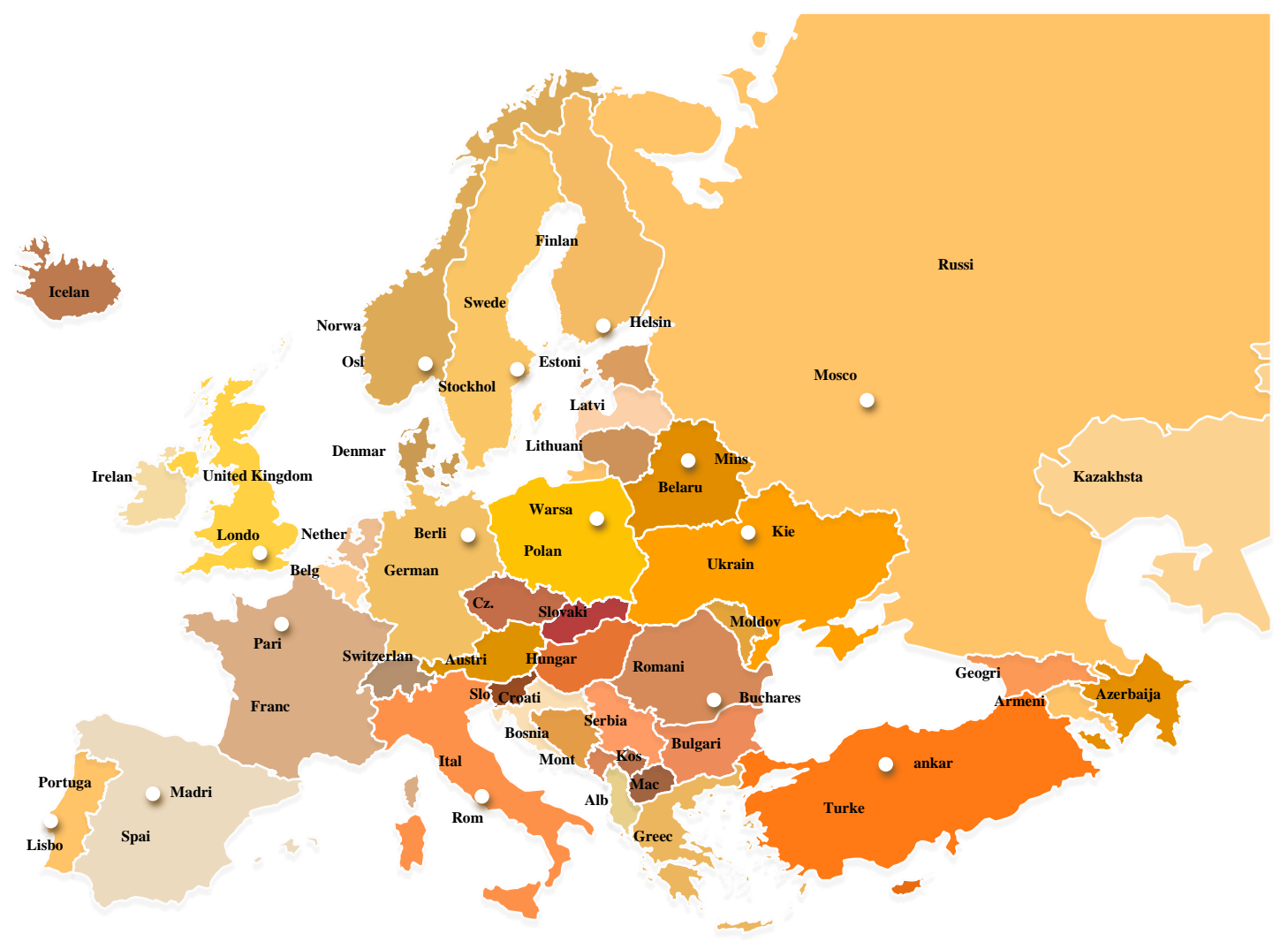

Figure 2. Map of states of the European Continent 
Of course, this conceptual digital spirit of the architectural design will involve more than $741,447,158$ inhabitants of the continent of Europe, with a total area of $10,180,000 \mathrm{~km}^{2}$, and the geographical entirety of 50 sovereign states [1].

\section{DISCUSSION}

The inventiveness of contemporary cities results in changing rapidly the space conditions. Traditionally designed buildings often cannot cope with this trend, with the appearance of such ever-changing demands. This professional phenomenon creates a new momentum, a concept and a new type of architectural structures. In these cases, buildings should be able to interact actively with the environment and with the ever-evolving user requirements. Consequently, the realization of architecture would no longer involve the creation and implementing the projects for fixed spatial interventions, but should go beyond, architecture should evolve into making adaptive-interactive design, where creative artistry will focus not only on creating physical structures, but also generating their dynamic interaction between urban and architectural environment.
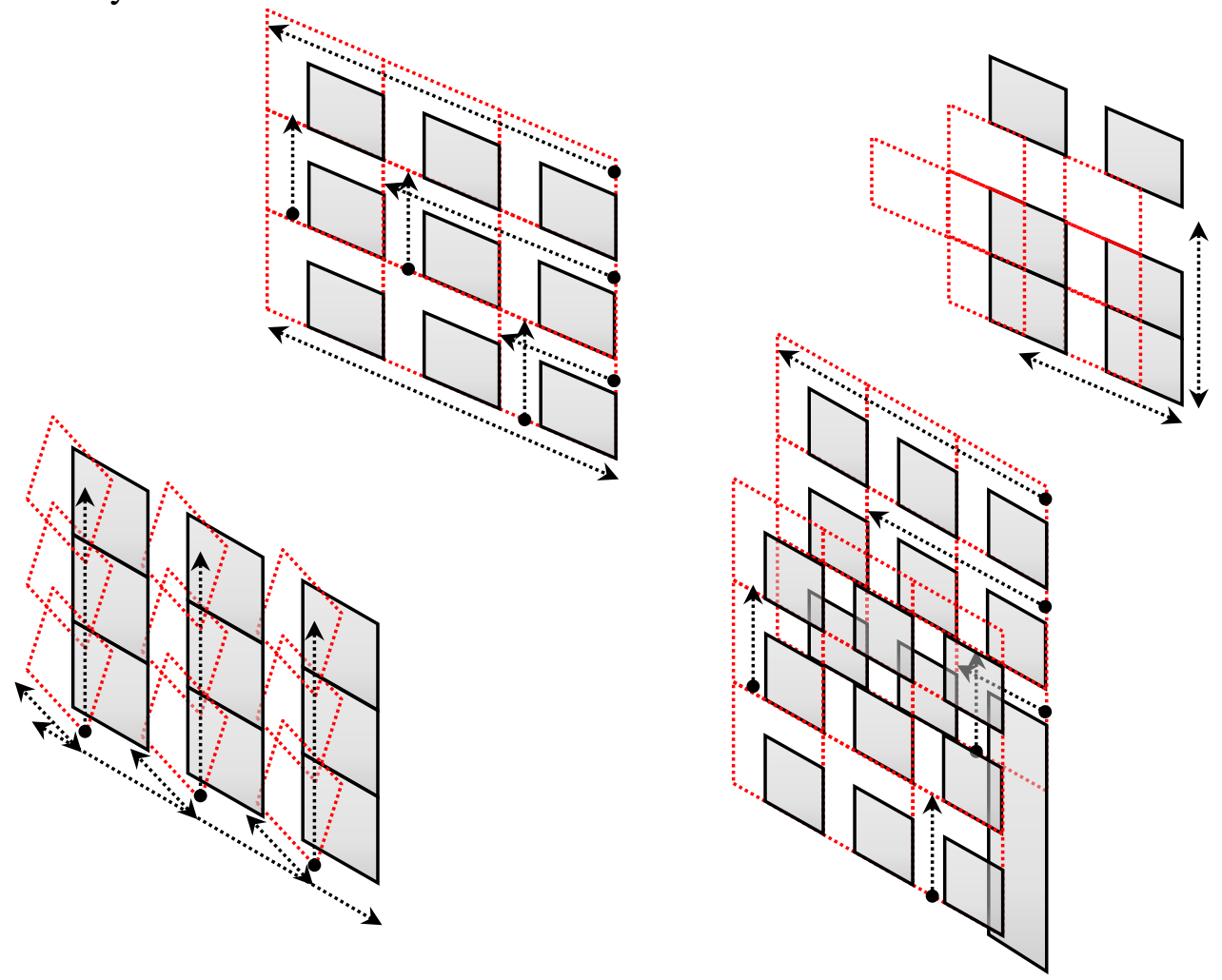

Figure 3. Interactive architecture, moving surfaces of architectural structures in many directions. 


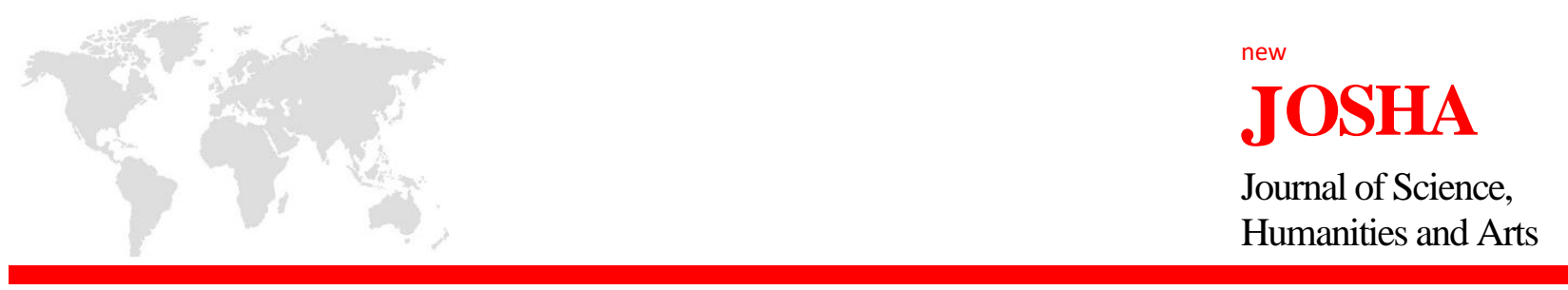

February, 2019

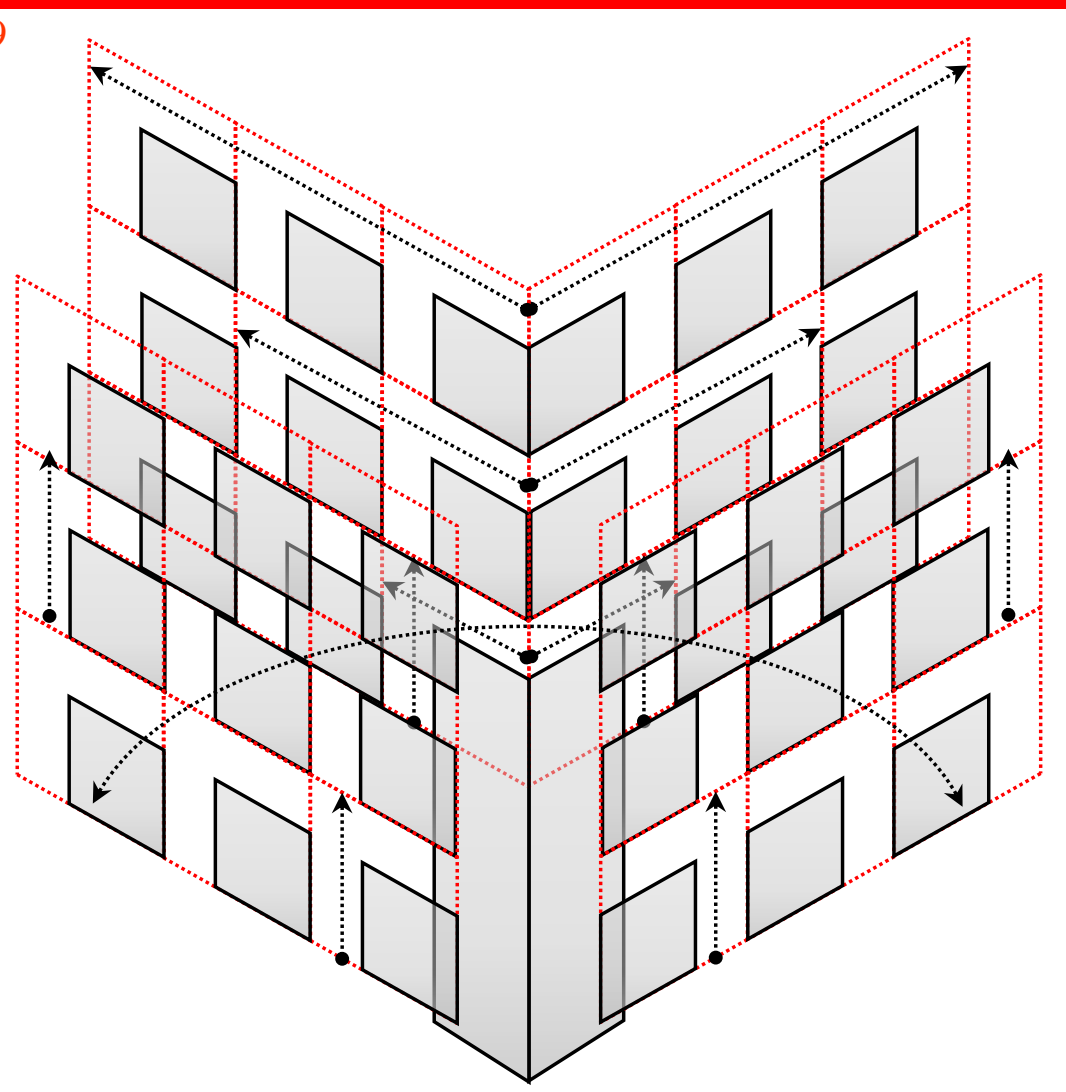

Volume 6, Issue 2

Figure 4. Interactive architecture, ways of moving surfaces of architectural structures in two directions, and under a certain angle.
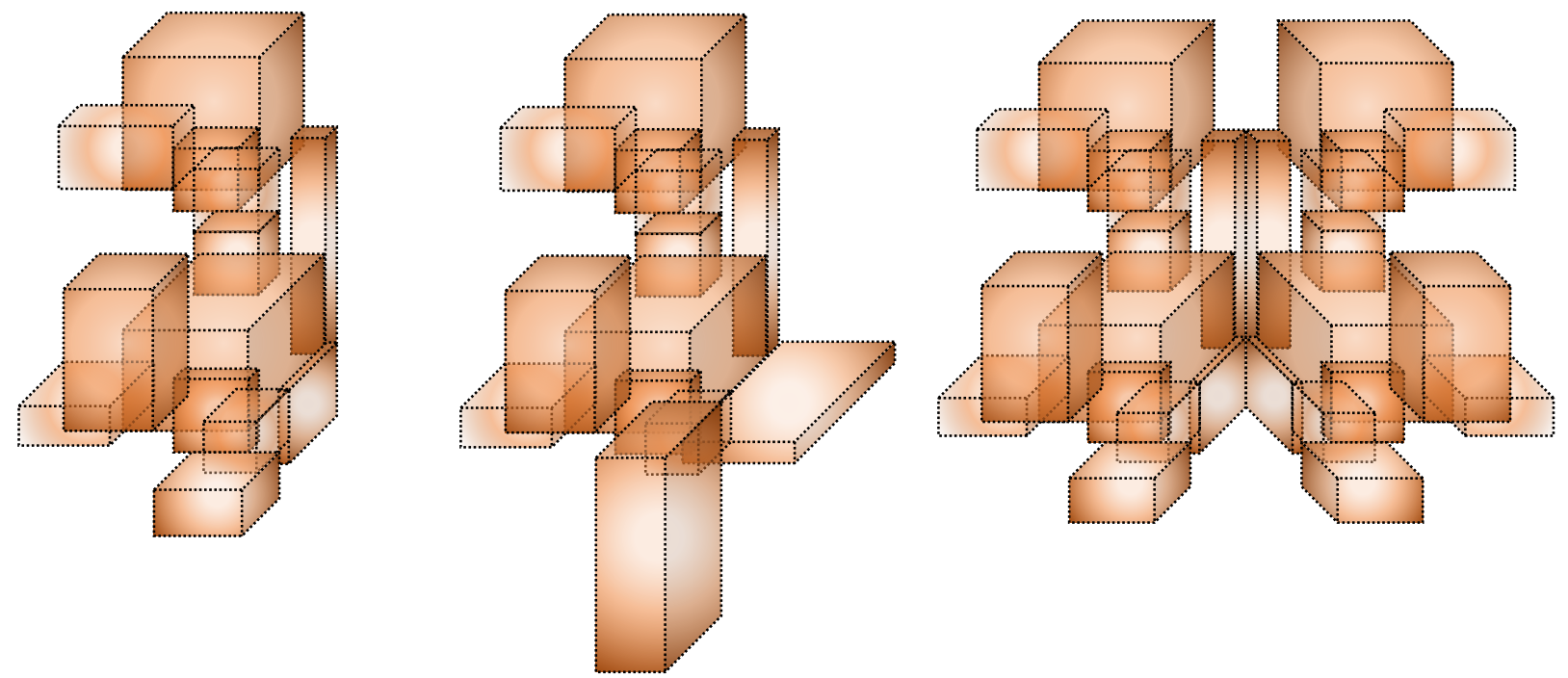

Figure 5. Interactive architecture, the volumetric architectural complexity of functional compositions - complex space structures. 


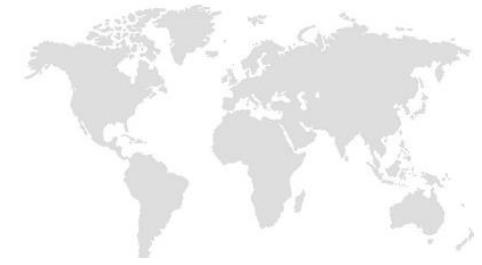

Journal of Science, Humanities and Arts

February, 2019

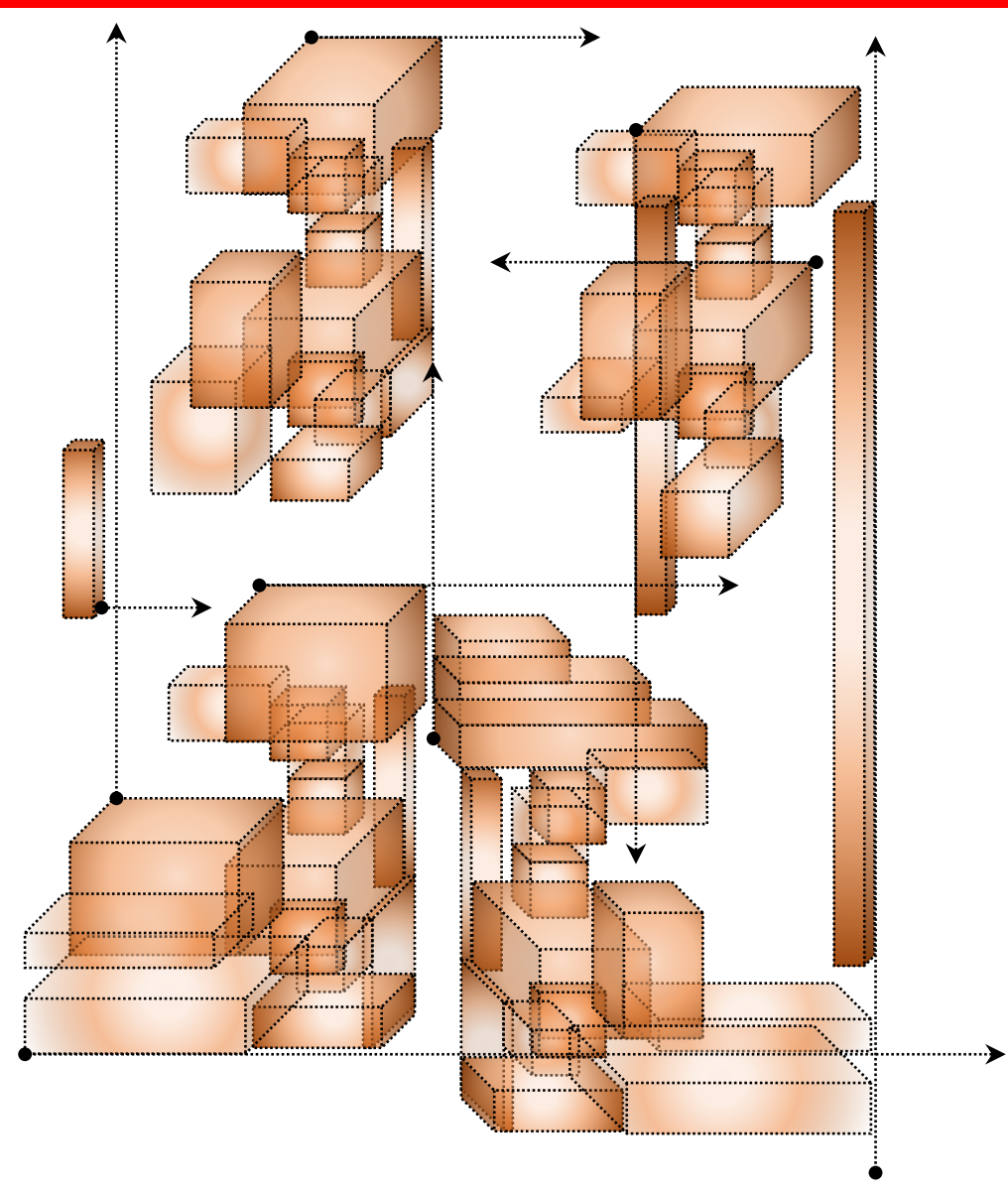

Volume 6, Issue 2

Figure 6. Interactive architectures, architectural development and interdisciplinary evolutionary interaction of cybernetics, architecture, e-control and communication with automated systems.
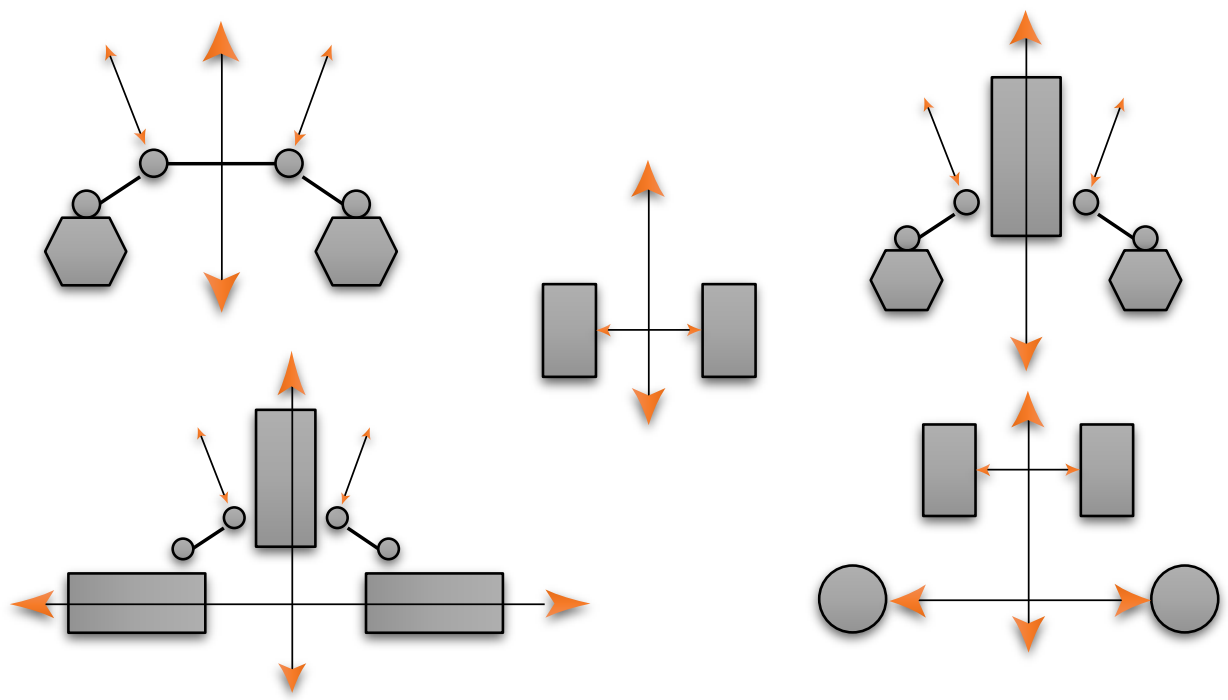

Figure 7. Composition of functional zones of complex structures. 


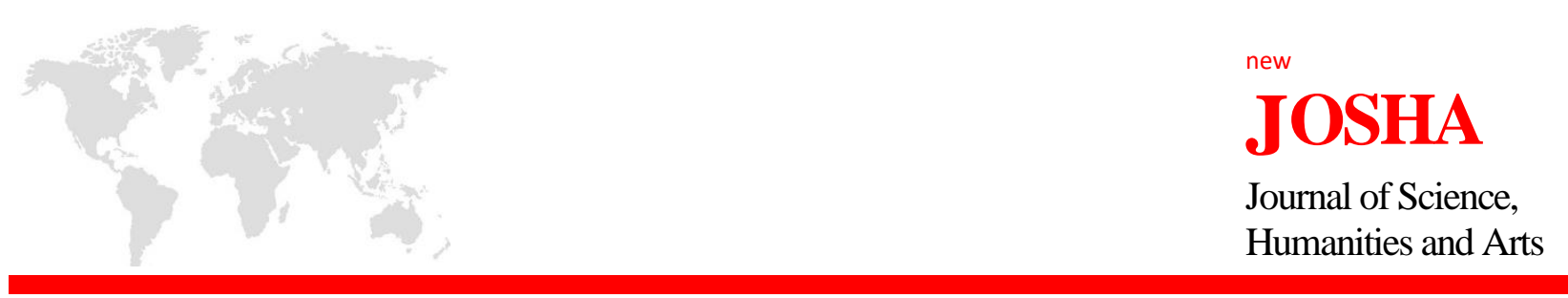

February, 2019

Volume 6, Issue 2

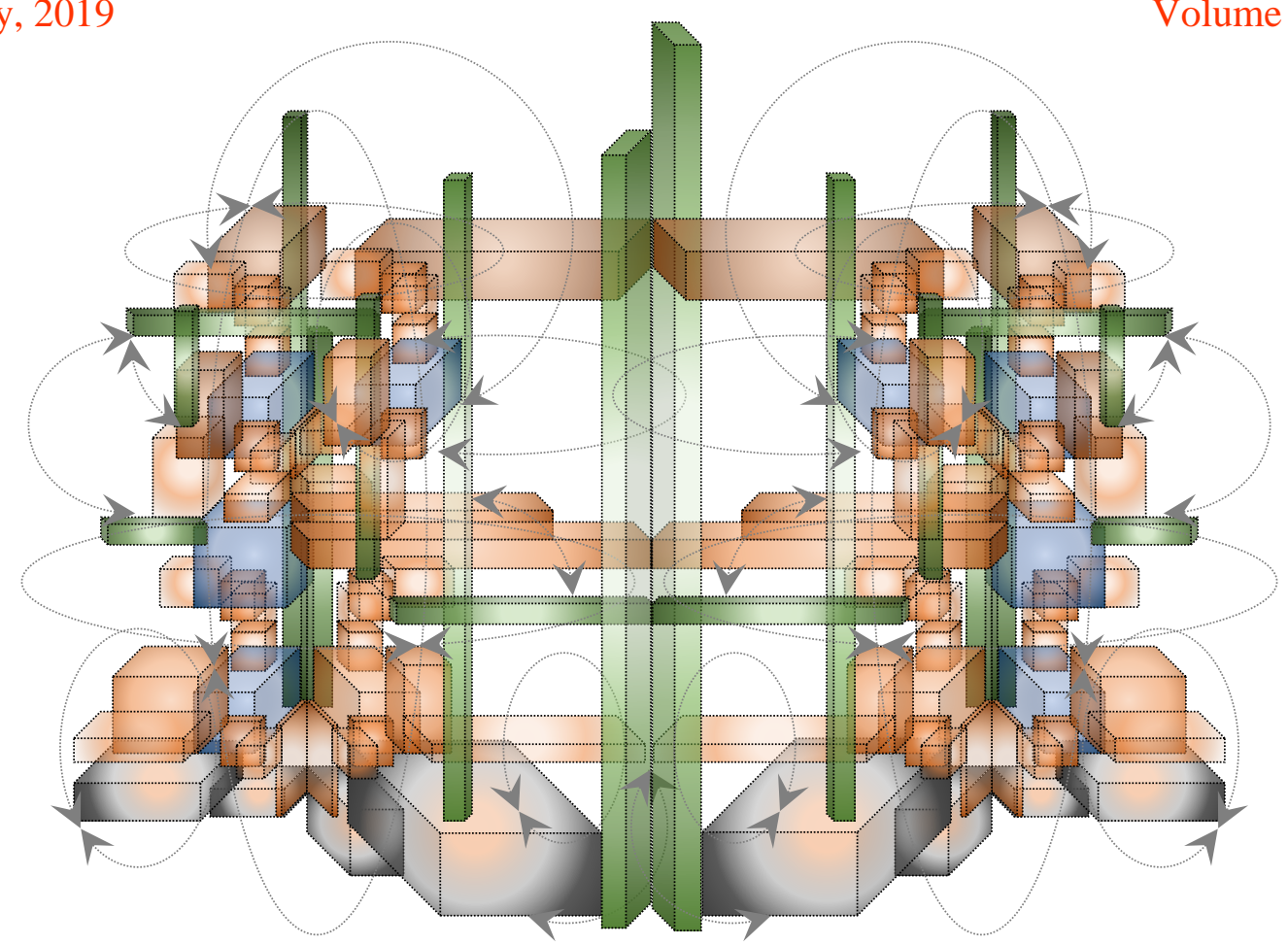

Figure 8. The volumetric architectural compositions of complex space structures.

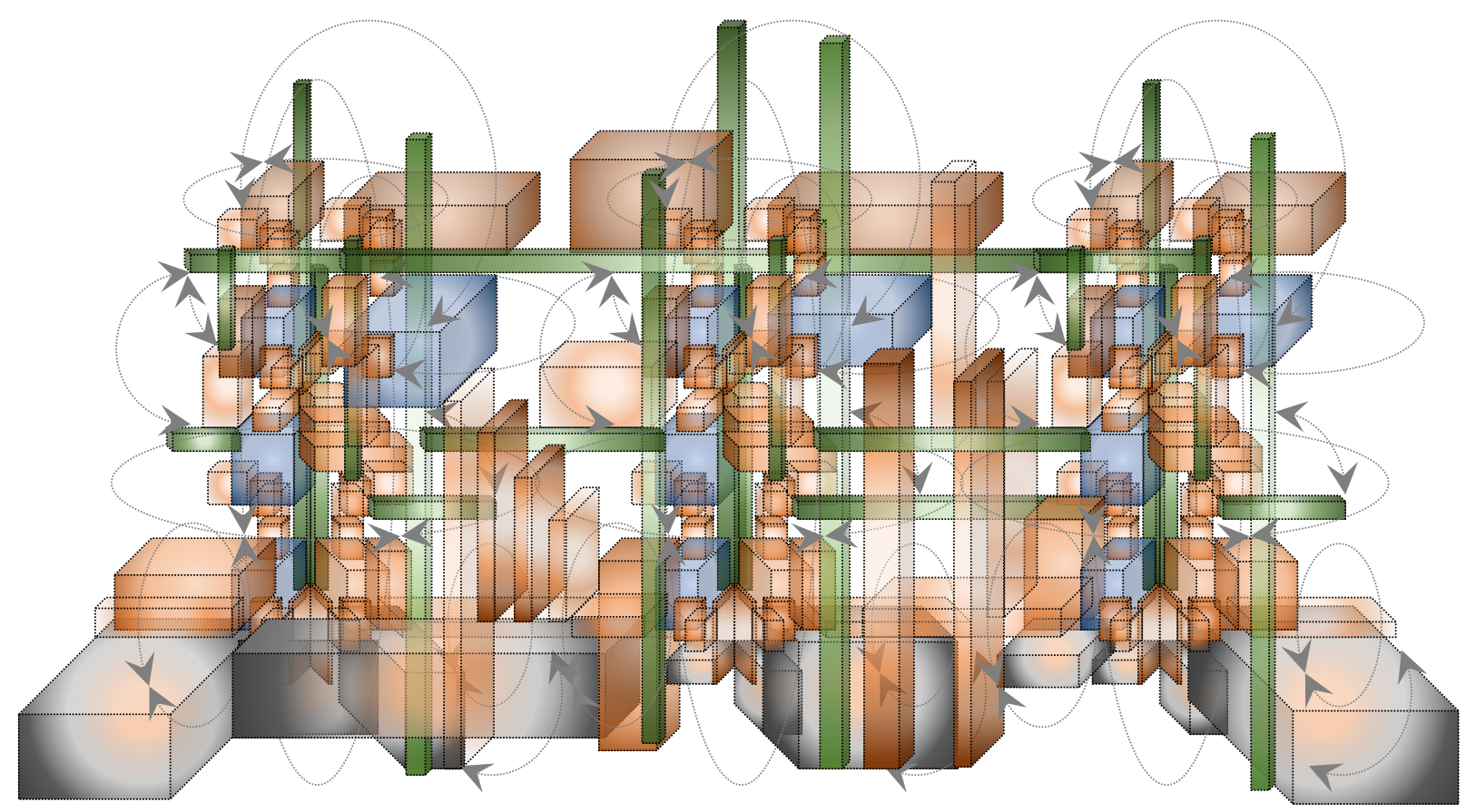

Figure 9. Interactive architecture, compositions of functional volumes of complex structures. Attribution License http://creativecommons.org/licenses/by/4.0/, which permits unrestricted use, provided the original author and source are credited. 

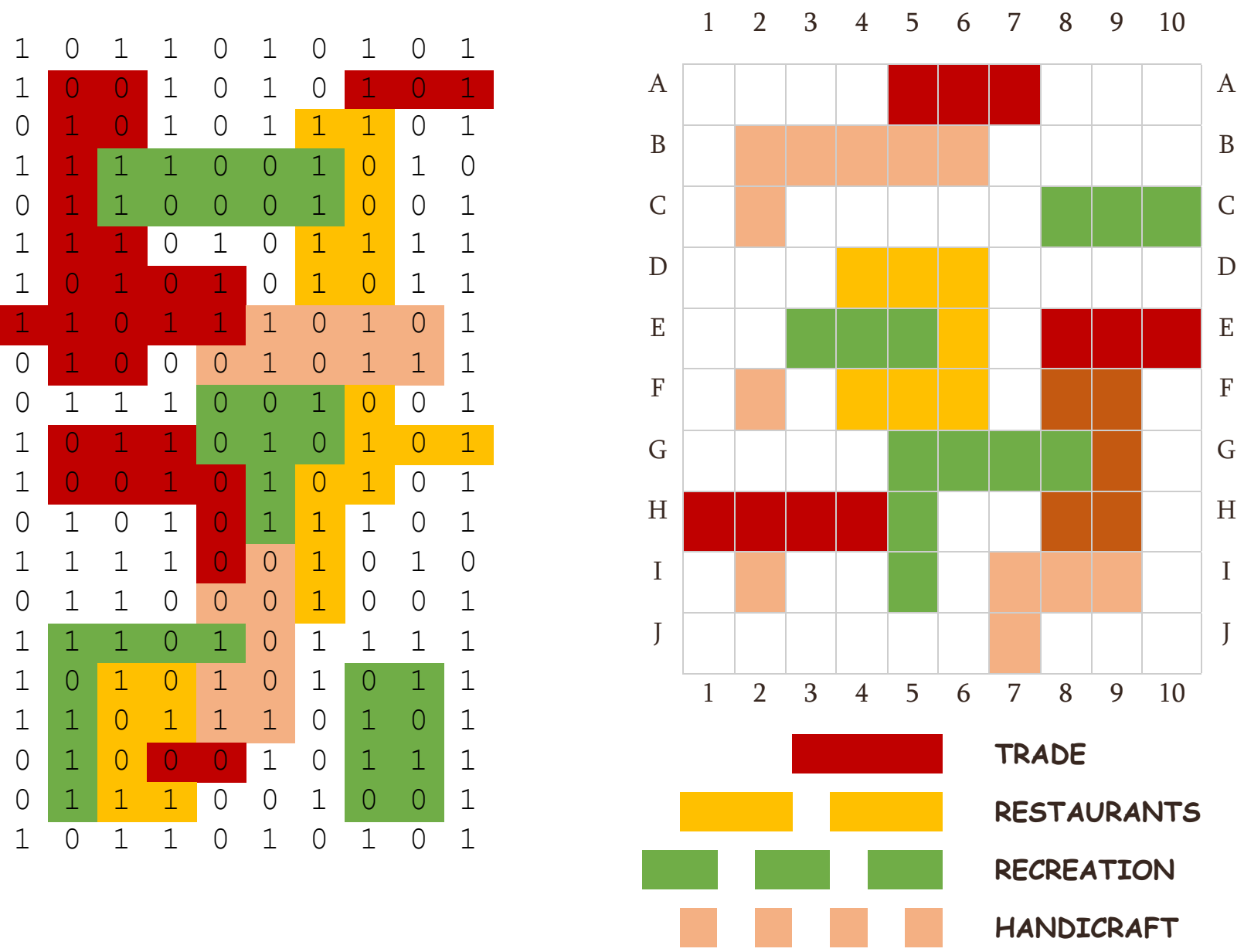

Figure 10. Interactive matrix, compositions of functional areas of complex structures.

In recent decades, we evidently recognize a particular interest of architects in designing computer game environments and structures, providing users with the ability to create certain interactive environments, accomplished by the technology of the computer-generated imagery. In those games, according to the designer Katie Salen, we can see the connection between the role of creation, imagination and the development of architecture. Therefore, games on the one hand, and interactive architecture on the other hand, share methodology, share techniques, share opportunities to orient the architecture practice in the direction of understanding virtual space in the context of volumetric and structural interaction, Salen, 2006 [5,6]. The time and space relationship in these virtual environments inspire the participants imagination and emphasizes the 
understanding of the imaginary of the wholeness's in relation to: configurations, space, time, and interactive actions to control the game. However, imagination is a very creative and complex act, especially when used for artistic aspiration. In the understanding of nowadays architects, digital interpretation of imagination represents the framework mechanism to deny the previous traditional archetypes, in the favor of a futuristic and interactive architecture. Hence, in this style of the approaches to the imaginative creativity, we do not focus solely on the creation of the avant-garde, but also to oppose, revolt, and discharge the barrier design rules. Of course, all these contradictions in the process of architectural creation represent an interesting challenge, and motivation to explore further [6].

\section{CONCLUSION}

Featuring the trio of sensors, processors and effectors, embedded as a core part of its nature and functioning motion of the variable elements in the architectural structure, transforms the perception and understanding of architectural buildings from that passive one, into an active architecture composition, respectively, the targeted feature can now change with an automated software in order to satisfy the individual requirements or community needs.

\section{REFERENCES}

[1] Wikipedia. (2019). Interactive Architecture. [Accessed:10 February 2019].

[2] 4dspace: Architectural Design, Interactive Architecture, Vol 75, No 1 Jan/Feb 2005. Published in Great Britain in 2005 by Wiley- Academy, a division of John Wiley \& Sons Ltd Copyright $(\odot)$ 2005, John Wiley \& Sons Ltd, The Atrium, Southern Gate, Chichester, West Sussex PO19 8 SQ, England.

[3] 4dsocial: Architectural Design, Interactive Design Environments, Vol 77, No 4 July/August 2007. Published in Great Britain in 2007 by Wiley- Academy, a division of John Wiley \& Sons Ltd Copyright @ 2007, John Wiley \& Sons Ltd, The Atrium, Southern Gate, Chichester, West Sussex PO19 8SQ, England.

[4] 4d Territory: Architectural Design, Territory: Architecture Beyond Environment, Vol 80, No 3 May/June 2010. Published in Great Britain in 2010 by Wiley- Academy, a division of John Wiley \& Sons Ltd Copyright $\odot$ 2010 , John Wiley \& Sons Ltd, The Atrium, Southern Gate, Chichester, West Sussex PO19 8SQ, England.

[5] Katie Salen (2006). Game design, playful learning. https://www.katiesalen.me/publications/

[6] Eds: Friedrich von Borries, Steffen P. Walz, Matthias Böttger. Space Time Play. Computer Games, Architecture and Urbanism: The Next Level. Birkhäuser Verlag AG 2007. Basel, Switzerland. 